\title{
KARADUTTAN (MORUS NIGRA L.) ANTİOKSİDAN BİLEŞİKLERİN KROMATOGRAFIK YÖNTEMLERLE İZOLASYONU VE TAYİNİ
}

\author{
Önder Aybastier* \\ Bursa Uludağ Üniversitesi, Fen Edebiyat Fakültesi, Kimya Bölümü, Bursa, Türkiye
}

Geliş / Received: 30.09.2020; Kabul / Accepted: 04.12.2020; Online bask1 / Published online: 23.12.2020

Aybastıer, Ö. (2020). Karaduttan (Morus Nigra L.) antioksidan bileşiklerin kromatografik yöntemlerle izolasyonu ve tayini. GIDA (2021) 46 (1) 32-41 doi: 10.15237/gida.GD20114

Aybastier, Ö. (2020). Isolation and determination of antioxidant compounds from black mulberry (Morus Nigra L.) by chromatographic methods. GIDA (2021) 46 (1) 32-41 doi: 10.15237/gida.GD20114

\section{ÖZ}

Karadut ülkemizde ve dünyanın pek çok bölgesinde tüketilen meyvelerden biridir. Bu çalş̧mada karadut meyvesinin suyu elde edilerek, kolon kromatografisi ile içeriğindeki antioksidan maddeler saflaşturlmıştır. Kolon kromatografisi sonucu 4 ayrı fraksiyon elde edilmiştir. Her bir fraksiyon ve karadut suyunun toplam fenolik madde içeriği ve antioksidan kapasitesi sırasıyla Folin-Ciocalteu ve ABTS yöntemleri ile belirlenmiştir. Ayrıca her bir fraksiyon ve karadut suyunun HPLC (yüksek performanslı sıvı kromatografi) analizleri yapılarak içerdiği antioksidan maddeler kantitatif olarak analiz edilmiştir. Karadut meyvesinin içerdiği temel fenolik madde siyanidin-3-glikozit olarak belirlenmiştir. Kolon kromatografisi ile karadutun içerdiği antioksidan maddeler \%80'in üzerinde geri kazanımla saflaşturlmıştr. Karadut meyvesinin önemli bir antosiyanin kaynağı olduğu ve kolon kromatografisi ile bu antosiyaninlerin saflaşturlabileceği ortaya konulmuştur.

Anahtar kelimeler: Karadut, izolasyon, antioksidan, fenolik madde, kromatografi

\section{ISOLATION AND DETERMINATION OF ANTIOXIDANT COMPOUNDS FROM BLACK MULBERRY (MORUS NIGRA L.) BY CHROMATOGRAPHIC METHODS}

\begin{abstract}
Black mulberry is one of the fruits consumed in our country and in many regions of the world. In this study, the juice of the black mulberry fruit was obtained and the antioxidant substances in its content were purified by column chromatography. Four fractions were obtained by column chromatography. Total phenolic content and antioxidant capacity of each fraction and black mulberry juice were determined by Folin-Ciocalteu and ABTS methods, respectively. Furthermore, each fraction and black mulberry juice were analyzed by HPLC (high performance liquid chromatography) for quantitatively determining their antioxidant substances. The main phenolic substance contained in the black mulberry fruit was determined as cyanidin-3-glucoside. The antioxidant substances contained in black mulberry were purified with recovery over $80 \%$ by column chromatography. It has been revealed that the black mulberry fruit is an important anthocyanin source and these anthocyanins can be purified by column chromatography.
\end{abstract}

Keywords: Black mulberry, isolation, antioxidant, phenolic compound, chromatography

${ }^{*}$ Yazışmalardan sorumlu yazar / Corresponding author

\aybastier@uludag.edu.tr

(2) (+90) 2242941738

悬 $(+90) 2242941899$

Önder Aybastıer; ORCID no: 0000-0002-0380-1992 


\section{GİRIŞ}

Dut ağac1, Moraceae (dutgiller) ailesinin Morus cinsine ait bir ağaçtır ve dünyanın birçok ılıman bölgesinde yaygın olarak bulunmaktadır. Beyaz dut (Morus alba L.), kirmiz1 dut (Morus rubra L.) ve karadut (Morus nigra L.) en çok bilinen ve araşturllan dut türleridir. Karadut meyveleri güzel bir tada ve yüksek besin değerlerine sahiptir. Bu nedenle dünyada yaygin olarak yetiştirilmektedir. (Dalmagro vd., 2019; Shekarabi vd., 2020).

Karadut meyvesi, taze meyve, kuru meyve, melas ve meyve suyu olarak tüketilebilmektedir (Kutlu vd., 2011). Taze yenildiğinde çok hoş bir tadı olan bu meyve reçel, meyve suları, likörler, doğal boyaların yanı sıra kozmetik endüstrisinde de kullanilır. Dut meyvesi, meyve ve sebzeler arasinda antioksidan olarak en zengin olanlardan biridir. Dutlar arasında, karadut meyveleri en yüksek miktarda fenolik bileşik içeren türdür. Karadutun özellikle antosiyaninler, flavonoidler ve fenolik bileşikler bakımından zengin olduğu belirlenmiştir. Meyvelerin antioksidan içeriği dut ağacinın yetiştiği toprağa, bulunduğu coğrafi konumuna ve yetiştirme koşullarına bağlıdır (Kostic vd., 2019).

Karadutun fenolik bileşikler, organik asitler ve şeker içeriği nedeniyle insan sağllğı ve beslenmesinde önemli etkileri olduğunu yapılan çalışmalarla ortaya konmuştur (Gündoğdu vd., 2011). Karadutun antioksidan özellikleri yapısında bulunan fenolik bileşiklerle, özellikle karaduta rengini veren antosiyaninlerle ilişkilendirilir. Antosiyaninler, antosiyanidinlere bir veya birkaç şeker grubunun bağlanmasiyla oluşan glikozitleridir. Antosiyaninler, şeker içermeyen antosiyanidin aglikonları ve şeker içeren antosiyanin glikozitleri olarak iki alt gruba ayrilır. Literatürde 500'den fazla farklı antosiyanin olduğu rapor edilmiştir. Meyve ve sebzelerde en yaygin bulunan alt antosiyanidin, siyanidin (\%50), delfinidin (\%12), pelargonidin (\%12), peonidin $(\% 12)$, petunidin (\%7) ve malvidindir (\%7). Antosiyanidinlerin 3-glikozit, 3,5- ve 3,7diglikozit türevleri daha bol bulunur ve 3 -glikozit türevleri 3,5-diglikozitlerden 2,5 kat daha fazladır. Doğadaki en yaygin antosiyanin siyanidin-3glikozittir. (Ovando vd., 2009).
Fenolik bileşikler, dejeneratif hastalıklanın önlenmesinde yüksek antioksidan özellikleri nedeniyle dikkat çekmektedirler. (Suh vd., 2003). Antosiyaninler, serbest radikalleri sönümleyerek çevrelerine zarar vermelerini engelleyen önemli bir suda çözünür fenolik pigment grubudur (Shekarabi vd., 2020). Antosiyaninler; meyve ve sebzelere maviden kırmızıya kadar uzanan geniş aralıktaki renklerini veren maddelerdir. Antosiyaninlerin rengi bulunduğu ortamdaki konsantrasyonuna, ortamın $\mathrm{pH}$ değerine, ortamda kopigment bulunup bulunmamasına bağlı olarak değişebilmektedir. Ortamın kimyasal özelliklerinden $\mathrm{pH}$, antosiyaninlerin rengi üzerinde en etkili olan parametredir. Genellikle $\mathrm{pH}$ yükseldikçe renklerini kaybederler veya renkler açlır. Antosiyoninler asidik ortamda kırmızı, nötr ortamda mor, bazik ortamda maviyeşil-menekşe, kuvvetli bazik ortamda mavi renk alır (Espin vd., 2000; Ananga vd., 2013).

Antosiyaninler çeşitli gıdaların renklendirilmesinde yüksek boyama güçleri nedeniyle boyar madde olarak kullanılmaktadırlar. Antosiyaninler suda çözünebildikleri için sulu g1da sistemlerine kolaylikla katulabilmektedirler. Antosiyaninlerin hem gidalara çekici renk özellikleri kazandırdıklanı hem de yüksek antioksidan kapasiteleri nedeniyle eklendikleri gıdaların oksidatif stabilitelerini arttırarak bozulmaya karşı da korudukları belirlenmiştir. (Katsube vd., 2006; Palonen ve Weber, 2019).

Karadutun içeriğinde bulunan başlica antosiyaninler, akciğer kanseri hücreleri üzerinde inhibe edici bir etkiye sahip olduğu bildirilen siyanidin-3-glikozit, siyanidin-3-rutinozit, pelargonidin-3-glikozit ve pelargonidin-3rutinozittir. Antosiyaninler ağız ve diş hastalıkları, hipertansiyon, diyabet, anemi, kanser gibi çeşitli hastalıklara karşı kullanılabilen bileşiklerdir (Suh vd., 2003; Chen vd., 2006; Mahesh vd., 2017). Siyanidinin DNA'y1 koruyucu etkisi DNA ile arasında bir kompleks oluştuğu öne sürülerek açıklanmışır. Bu kompleksin oluşumunun hem siyanidini hem de DNA'yı özellikle hidroksil radikalinin saldırısı ile oluşan oksidatif hasardan koruduğu belirtilmiştir (Sarma ve Sharma, 1999). 
Yapılan çalışmalarla sağlığa yararlı olan bitki etken maddelerinin saflaştırılması ve kozmetik, ilaç, gıda gibi alanlarda kullanılması yaygınlaşmaktadır. Kimyasal yapılanına göre bitkilerde bulunan fenolik bileşiklerin ekstraksiyon ve izolasyon yöntemleri farklilik göstermektedir (Pelvan, 2020). Antosiyaninler en iyi doğal gida boyalarından olmalarına rağmen, elde edilmelerinin zor olması ve kararlı yapiya sahip olmamalarından dolayı kullanımları ve yaygınlıkları yeterince artmamaktadır. Antosiyaninler, içime hazır içeceklerde kırmızı rengi vermek için kullanılabilirler. Bu amaçla çok düşük konsatrasyonlarda antosiyanin kullanımı yeterlidir. Meyveli yoğurtlar ve şekerlemelerde de renklendirici olarak kullanilabilirler. Antosiyaninler doğal renk verici maddeler olduğundan, birçok gidanın renklendirilmesinde sentetik boyar maddelere önemli bir alternatif olarak görülmektedir. (Hepsağ vd., 2012; Khoo vd., 2017).

$\mathrm{Bu}$ çalışmada ülkemizin pek çok bölgesinde yetiştirilen ve tüketilen bir meyve olduğu için antosiyanin kaynağ1 olarak karadut seçilmiştir. Tokat/Türkiye'den toplanan karadutlardan karadut suyu elde edilerek, kolon kromatografisi yöntemi ile karadut suyunun içerdiği antioksidan maddelerin izolasyonu gerçekleştirilmiştir. Karadut suyu ve elde edilen 4 fraksiyonun ABTS yöntemi ile antioksidan kapasite, Folin-Ciocalteu yöntemi ile toplam fenolik madde tayinleri yapılmış, her birinin içerdiği antioksidan maddeler HPLC ile kantitatif olarak belirlenmiştir.

\section{MATERYAL VE YÖNTEM}

\section{Materyal}

Karadut meyvesi Tokat ili merkezinde bulunan bir ağaçtan toplamıştur. Metanol, formik asit, asetonitril ve $\mathrm{HCl}$ Merck'ten (Darmstadt, Almanya) satın alınmıştır. Gallik asit, ABTS (2,2'azino-bis(3-etilbenztiazolin-6-sülfonik asit)), etanol, Folin-Ciocalteu reaktifi, ( \pm )-6-hidroksi2,5,7,8-tetrametilkroman-2-karboksilik asit (troloks), siyanidin-3-glikozit (kuromanin), siyanidin-3-rutinozit (kerasiyanin), pelargonidin3-glikozit (kallistefin) ve protokatekuik asit SigmaAldrich'ten (St. Louis, MO., ABD) satn alınmıştur. Tüm deneysel işlemlerde analitik saflıkta kimyasallar ve ultra saf su kullanılmıştır.

\section{Karadut suyu hazırlanmas1}

Toplanan karadut (Morus nigra L.) meyvesi rondodan geçirildikten sonra falkon tüplere alınarak sanrifüjlenmiştir. $\mathrm{Bu}$ işlem santrifüj sonrası çökelek kalmayana kadar tekrar edilmiştir. 5000 rpm'de 15 dakika sonunda üstte kalan sulu faz alınarak cam kavanoz içinde dondurucuda -24 oC'de muhafaza edilmiştir.

\section{Karadut suyundan fenolik maddelerin izolasyonu}

Karadut suyundan fenolik maddelerin izolasyonu için kolon kromatografisi kullanılmıştır. $10 \mathrm{~mm}$ çapındaki cam kolon, 25-100 $\mu \mathrm{m}$ tanecik boyutuna sahip Sephadex LH-20 dolgu malzemesi ile $400 \mathrm{~mm}$ yüksekliğinde doldurulmuştur. En uygun hareketli fazın seçilmesi için çeşitli denemeler yapılmış ve kullanılacak hareketli faz hacimce $\% 20$ saf su $\% 80$ metanol olarak belirlenmiştir. Kolon dolgu malzemesi ile doldurulduktan sonra $100 \mathrm{~mL}$ daha hareketli faz geçirilerek şartlandırma yapılmıştır. Kolondan akış bir peristaltik pompa yardımıyla sağlanmıştır. Ortalama akış hızı $0.22 \mathrm{~mL} / \mathrm{dk}$ olarak çalışılmıştır. $5 \mathrm{~mL}$ karadut suyu $2.5 \mathrm{~mL}$ hareketli faz ile kanşturılarak kolona üstten verilmiştir. Daha sonra hareketli faz eklenmeye devam edilerek, kolondan çıkan hareketli faz tüplere 3'er $\mathrm{mL}$ alınarak izolasyon işlemi gerçekleştirilmiştir. Her bir tüpün 280, 360, 530 nm'deki absorbansları ölçülerek grafiğe geçirilmiştir.

\section{Toplam fenolik madde tayini}

Toplam fenolik madde tayini Folin-Ciocalteu yöntemi kullanılarak yapılmıştır (Aybastıer vd., 2013). Lowry A çözeltisi $0.1 \mathrm{M} \mathrm{NaOH}$ içinde $\% 2$ 'lik $\mathrm{Na}_{2} \mathrm{CO}_{3}$ olacak şekilde ve Lowry $\mathrm{B}$ çözeltisi \%1'lik $\mathrm{NaKC}_{4} \mathrm{H}_{4} \mathrm{O}_{6}$ içinde $\% 0.5 \mathrm{CuSO}_{4}$ olacak şekilde hazırlanmıştır. Lowry C çözeltisi, Lowry A ve Lowry B 50:1 (h/h) oranında karıştrrılarak hazırlanmıştır. Deney tüplerine 0.1 $\mathrm{mL}$ örnek, $1.9 \mathrm{~mL}$ saf su, $2.5 \mathrm{~mL}$ Lowry C çözeltisi ve $0.25 \mathrm{~mL}$ Folin-Ciocalteu reaktifi eklenip çalkalanmıştır. $30 \mathrm{dk}$ karanlıkta bekletildikten sonra ultraviyole-görünür bölge 
spektrofotometresi ile $750 \mathrm{~nm}$ 'de absorbanslar ölçülmüştür. Standart madde olarak gallik asit kullanılarak, farklı konsantrasyonlara sahip çözeltileri yardımıyla kalibrasyon grafiği oluşturulmuştur. Örnekler ile aynı işlemler yapılıp absorbanslar ölçüldükten sonra gallik asit konsantrasyonuna karşlık absorbans grafiği çizilmiştir. En küçük kareler yöntemiyle doğru denklemi belirlenerek numuneler için toplam fenolik madde miktarları $\mathrm{mg}$ gallik asit/100 mL örnek şeklinde hesaplanmıştır.

\section{Antioksidan kapasite tayini}

Antioksidan kapasite tayini ABTS yöntemi kullanılarak yapılmıştır (Aybastıer vd., 2013). 6 $\mathrm{mM}$ ABTS stok çözeltisi etanol içinde hazırlanmıştır. Analizler için 1:10 oranında saf su ile seyreltilerek kullanılmıştır. Analiz için $0.1 \mathrm{~mL}$ örnek üzerine $3.9 \mathrm{~mL}$ etanol ve seyreltilmiş ABTS çözeltisinden $1.0 \mathrm{~mL}$ eklenmiştir. $6 \mathrm{dk}$ bekledikten sonra, ultraviyole-görünür bölge spektrofotometresi ile $734 \mathrm{~nm}$ 'de absorbanslar ölçülmüştür. Antioksidan madde içermeyen kör örneğin absorbans değerine göre her bir numunenin $\%$ inhibisyon değeri hesaplanmıştır. Standart madde olarak troloks kullanilarak, farkl1 konsantrasyonlara sahip çözeltileri yardımıyla kalibrasyon grafiği oluşturulmuştur. Troloks konsantrasyonuna karşl1ık \% inhibisyon grafiği çizilmiştir. En küçük kareler yöntemiyle doğru denklemi belirlenerek, numuneler için antioksidan kapasite değerleri $\mathrm{mg}$ troloks/100 mL örnek şeklinde hesaplanmıştır.

\section{HPLC analizi}

Agilent 1200 HPLC sistemi ve XBridge C18 (4.6 x $250 \mathrm{~mm}, \quad 3.5 \mu \mathrm{m})$ kolon kullanilarak kromatografik analizler gerçekleştirilmiştir. 0.5 $\mathrm{mL} / \mathrm{dk}$ hareketli faz akış hızı ve $10 \mu \mathrm{L}$ enjeksiyon hacmi ile çalışılmıştır. Analiz sırasında formik asittin sudaki \%1'lik (h/h) çözeltisi (çözücü A) ve asetonitrilden (çözücü B) oluşan gradient hareketli faz programı kullanılmıştur. 0-10 dk \%13 B, 10-20 dk \%41.5 B, 20-25 dk \%70 B, 25-35 dk $\% 10 \mathrm{~B}$ şeklinde gradient program uygulanmıştır. Kolon sicaklığ $25^{\circ} \mathrm{C}$ ve toplam analiz süresi 35 dk'dır. $280 \mathrm{~nm}$ dalgaboyunda protokatekuik asit, $530 \mathrm{~nm}$ dalgaboyunda siyanidin-3-glikozit, siyanidin-3-rutinosit ve pelargonidin-3-glikozit tayin edilmiştir. Farklı konsantrasyonlarda standart madde çözeltileri kullanılarak, konsantrasyon ile pik alanı arasında grafikler çizilmiştir. Grafiklerden en küçük kareler yöntemiyle elde edilen kalibrasyon denklemlerinde örneklerden elde edilen pik alanları yerine koyularak her bir maddenin miktarı $\mathrm{mg} / 100 \mathrm{~mL}$ örnek şeklinde hesaplanmıştır.

\section{SONUÇ VE TARTIŞMA \\ Karadut suyundan antosiyaninlerin izolasyonu}

Karadut, ülkemizde ve dünyanın pek çok bölgesinde yetişebilen bir meyvedir. Antioksidan özelliğinin yüksek olduğu daha önce yapilan çalışmalarda da belirtilmiştir. Antioksidan özelliğinin ana kaynağı, karaduta kırmızı rengini de veren antosiyaninlerdir. Sahip olduğu güzel lezzet ve zengin antioksidan içerik karadut meyvesini ve suyunu önemli bir antioksidan kaynağ1 haline getirmektedir. İçerdiği antosiyaninler izole edilerek doğal boyarmaddeler olduklar1 için özellikle gida sektöründe renklendirici olarak kullanilabilirler. Antosiyaninler antioksidan özelliklerinden dolay1 eklendikleri g1da ürününü renklendirdikleri gibi bozulmaya karşı da korunmasına da yardımc1 olurlar.

Karadut suyundaki antioksidan bileşiklerin izolasyonu kolon kromatografisi ile gerçekleştirilmiştir. Kullanılacak hareketli fazı belirlemek için, metanol, etanol, propanol, 2propanol denenmiştir. Bu alkoller ayrı ayrı karadut suyu ile karıştırılmış ve çökelek oluşumu gözlenmiştir. Alkil zinciri uzadıkça oluşan çökelek miktarının da arttı̆̆ tespit edilmiştir. Herhangi bir çökmenin gözlenmediği hacimce \%80 metanol$\% 20$ saf su karışımı en uygun hareketli faz olarak belirlenmiştir. Cam kolon dolgu malzemesi ile doldurulduktan sonra $100 \mathrm{~mL}$ daha hareketli faz geçirilerek kolon şartlandırılmıştır. $5.0 \mathrm{~mL}$ karadut suyu $2.5 \mathrm{~mL}$ hareketli faz ile karıştırıldıktan sonra kolona verilmiştir. Ardından kolondan 100 mL hareketli faz geçirilerek elüsyon gerçekleştirilmiştir. Kolondan çıkışında eluatlar her birinde 3'er $\mathrm{mL}$ olacak şekilde tüplere toplanmıştrr. Her bir tüpün 280, 360, 530 nm'deki absorbanslar1 ultraviyole-görünür bölge 
spektrofotometresinde ölçülerek grafiğe geçirilmiştir. Şekil 1'de verilen 280 nm'deki absorbaslara göre çizilen grafikten yararlanarak fraksiyonlar oluşturulmuştur. İçlerinde 3'er $\mathrm{mL}$ bulunan 35 tüpten 4 fraksiyon elde edilmiştir. 8 ile 11. tüpler birleştirilerek 1 . fraksiyon, 12 ile 17 . tüpler birleştirilerek 2. fraksiyon, 18 ile 23. tüpler birleştirilerek 3. fraksiyon, 24 ile 30. tüpler birleştirilerek 4. fraksiyon elde edilmiştir. 1 ile 7. tüpler ve 30 ile 35. tüpler arasında ölçüm alınan dalga boylarında herhangi bir absorpsiyon olmadığ1 için bu tüplerin karaduttan gelen herhangi bir madde içermediği kabul edilmiştir. Her bir fraksiyon döner buharlaştırıcı yardımıyla $50{ }^{\circ}$ C'de vakum altında $5 \mathrm{~mL}$ kalıncaya kadar buharlaştırlmıştr. 1. fraksiyon renksiz, 2. ve 3 . fraksiyon koyu kırmızı renkli, 4. fraksiyon pembe renkli olarak elde edilmiştir.

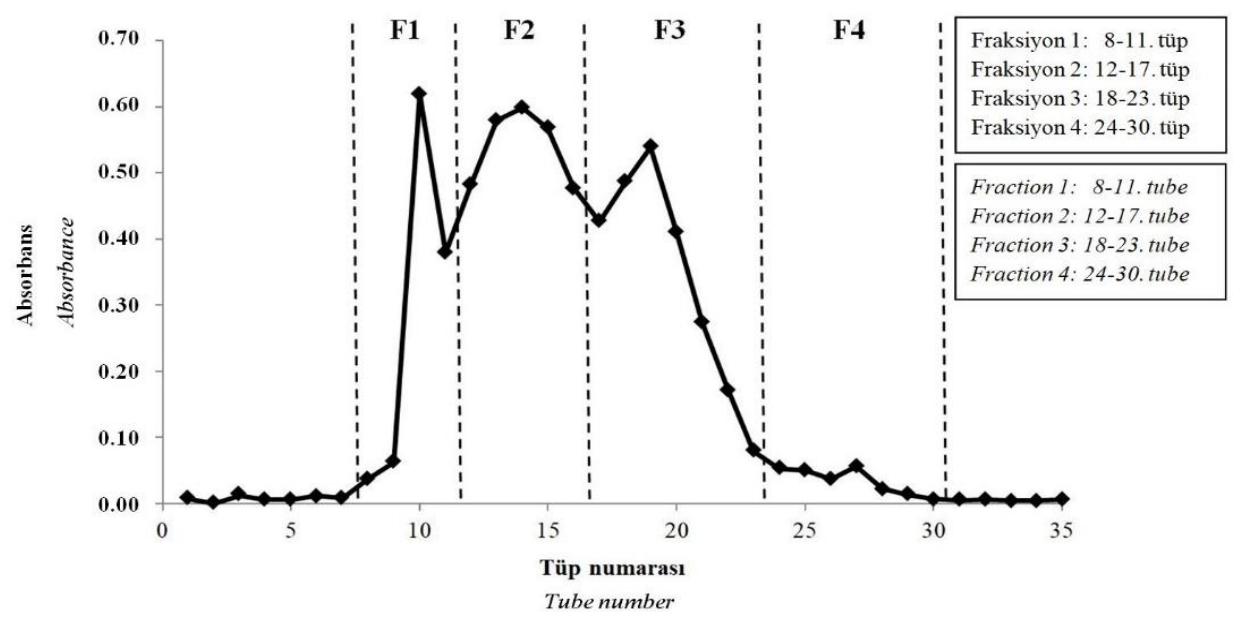

Şekil 1.280 nm'de tüp numarasına karşlık absorbans grafiği

Figure 1. Absorbance versus tube number plot at $280 \mathrm{~nm}$

\section{Toplam fenol ve antioksidan kapasite}

Her bir fraksiyon ve karadut suyu için ABTS yöntemi ile antioksidan kapasite, Folin-Ciocalteu yöntemi toplam fenolik madde analizleri yapılmıştur. Antioksidan kapasite ve toplam fenolik madde sonuçlan Çizelge 1'de verilmiştir. Fraksiyon 2 ve fraksiyon 3'ün diğer fraksiyonlara göre daha yüksek antioksidan kapasite ve toplam fenolik madde değerine sahip olduğu bulunmuştur. $\mathrm{Bu}$ fraksiyonların renkleri kırmızı olduğundan HPLC analizi öncesi antioksidan özelliklerinin karadutta bulunan çeşitli antosiyaninlerden kaynaklandığı düşünülmüsstür.

Fraksiyonların toplamı ile karadut suyunun antioksidan kapasite ve toplam fenolik madde değerleri karşılaştırıldığında, antioksidan kapasitede yaklaşık \%87 toplam fenolik madde de yaklaşık \%89 geri kazanım olduğu belirlenmiştir. Karadut meyvesinin çeşitli çözücülerle ekstrakte edilmesiyle yapılan çalışmalarda Uzun ve Bayır (2010), tarafindan toplam fenolik madde miktarı
456.13-477.13 mg gallik asit/100 g olarak bulunurken, Polat vd. (2019) tarafindan 101.1$664.2 \mathrm{mg}$ gallik asit/100 g olarak, Özgen vd. (2009) tarafindan ise $176.6-348.8 \mathrm{mg}$ gallik asit/100 g olarak belirlenmiştir. Söz edilen çalışmalarda toplam fenolik madde miktarı meyve ağırllı̆̆ üzerinden hesaplanırken, bu çalışmada meyve suyu hacmi üzerinden hesaplanmıştır. Meyvelerin antioksidan özellikleri, yetiştikleri bölge, toprak içeriği, iklim koşulları, toplanma zamanı gibi pek çok farklı değişkene bağlıdır. Ayrıca örnek hazırlama ve kullanılan analiz yöntemi de sonuçlar üzerine etki etmektedir.

Kolon kromatografisi ile hazırlanan fraksiyonların antioksidan içerikleri

Numunelerin içerdikleri antioksidan maddelerin ve miktarlarının belirlenmesi için HPLC analizleri gerçekleştirilmiştir. Karadut suyu ve her bir fraksiyon için yapılan HPLC analizleri sonucu elde edilen kromatogramlardaki piklerin alıkonma zamanı ve ultraviyole-görünür bölge spektrumları 
standartlar ile karşılaştırlarak hangi antioksidan maddeye ait olduğu belirlenmiştir. Antosiyanin standartlarının ve karadut suyunun kromatogramı Şekil 2'de, elde edilen sonuçlar Çizelge 2'de görülmektedir. Karadutun içerdiği temel fenolik madde bir antosiyanin olan siyanidin-3-glikozit olarak belirlenmiştir. Fraksiyonların içeriği incelendiğinde, protokatekuik asit antosiyaninlerden başarıly ayrilarak sadece fraksiyon 1'de gözlenmiştir. Karadut suyunun içeriğinde bulunan 3 antosiyaninin yapıları oldukça benzer olduğundan, fraksiyon 2'de siyandin-3-rutinozit en yüksek miktarda olmak üzere siyanidin-3-glikozit ve çok az miktarda pelargonidin-3-glikozit belirlenmiştir. Fraksiyon 3'de siyanidin-3-glikozit ve pelargonidin-3glikozit, fraksiyon 4'de ise sadece düşük miktarda siyanidin-3-glikozit tespit edilmiştir. Fraksiyonlardan elde edilen fenolik maddeler karadut suyu ile karşılaştırıldığında \%80-83 arasında geri kazanım olduğu görülmektedir. Karadutun içerdiği belirlenen fenolik maddelerin moleküler yapıları Şekil 3'de görülmektedir.

Çizelge 1. Karadut suyu ve fraksiyonların antioksidan kapasite ve toplam fenolik madde değerleri Table 1. Values of antioxidant capacity and total phenolic content of black mulberry juice and fractions

\begin{tabular}{|c|c|c|}
\hline & $\begin{array}{c}\text { Antioksidan Kapasite } \\
\text { (mg troloks/100 mL örnek) } \\
\text { Antioxidant Capacity } \\
\text { (mg trolox } / 100 \mathrm{~mL} \text { sample) }\end{array}$ & $\begin{array}{c}\text { Toplam Fenolik Madde } \\
\text { (mg gallik asit/100 mL örnek) } \\
\text { Total Phenolic Content } \\
\text { (mg gallic acid/100 mL sample) }\end{array}$ \\
\hline $\begin{array}{l}\text { Karadut suyu } \\
\text { Mulberry juice }\end{array}$ & $135.48 \pm 2.55$ & $168.74 \pm 3.83$ \\
\hline $\begin{array}{l}\text { Fraksiyon } 1 \\
\text { Fraction } 1\end{array}$ & $3.10 \pm 0.28$ & $4.96 \pm 0.36$ \\
\hline $\begin{array}{l}\text { Fraksiyon } 2 \\
\text { Fraction } 2\end{array}$ & $53.48 \pm 1.66$ & $55.66 \pm 5.02$ \\
\hline $\begin{array}{l}\text { Fraksiyon } 3 \\
\text { Fraction } 3\end{array}$ & $49.28 \pm 1.72$ & $74.02 \pm 6.24$ \\
\hline $\begin{array}{l}\text { Fraksiyon } 4 \\
\text { Fraction } 4\end{array}$ & $11.44 \pm 0.96$ & $16.32 \pm 1.40$ \\
\hline
\end{tabular}

Sonuçlar ortalama \pm standart sapma olarak verilmiştir.

Results are given as mean \pm standard deviation.

Çizelge 2. Karadut suyu ve fraksiyonların HPLC sonuçları (mg/100 mL örnek) Table 2. HPLC results of black mulberry juice and fractions

\begin{tabular}{lcccc}
\hline & $\begin{array}{c}\text { Siyanidin-3- } \\
\text { glikozit } \\
\text { Cyanidin-3- } \\
\text { glucoside }\end{array}$ & $\begin{array}{c}\text { Siyanidin-3- } \\
\text { rutinozit } \\
\text { Cyanidin-3- } \\
\text { rutinoside }\end{array}$ & $\begin{array}{c}\text { Pelargonidin-3- } \\
\text { glikozit } \\
\text { Pelargonidin-3- } \\
\text { glucoside }\end{array}$ & $\begin{array}{c}\text { Protokatekuik } \\
\text { asit } \\
\text { Protocatechuic acid }\end{array}$ \\
\hline $\begin{array}{l}\text { Karadut suyu } \\
\text { Mulberry juice }\end{array}$ & $48.42 \pm 0.72$ & $41.86 \pm 2.06$ & $5.32 \pm 0.39$ & $10.06 \pm 0.82$ \\
$\begin{array}{l}\text { Fraksiyon 1 } \\
\text { Fraction 1 } \\
\text { Fraksiyon 2 }\end{array}$ & - & - & - & $8.01 \pm 0.59$ \\
$\begin{array}{l}\text { Fraction 2 } \\
\text { Fraksiyon 3 }\end{array}$ & $6.40 \pm 0.42$ & $33.36 \pm 2.28$ & $0.92 \pm 0.05$ & - \\
$\begin{array}{l}\text { Fraction 3 } \\
\text { Fraksiyon 4 }\end{array}$ & $30.58 \pm 2.02$ & - & $3.48 \pm 0.22$ & - \\
Fraction 4 & $2.24 \pm 0.16$ & - & - & - \\
\hline
\end{tabular}

Sonuçlar ortalama \pm standart sapma olarak verilmiştir.

Results are given as mean土standard deviation. 

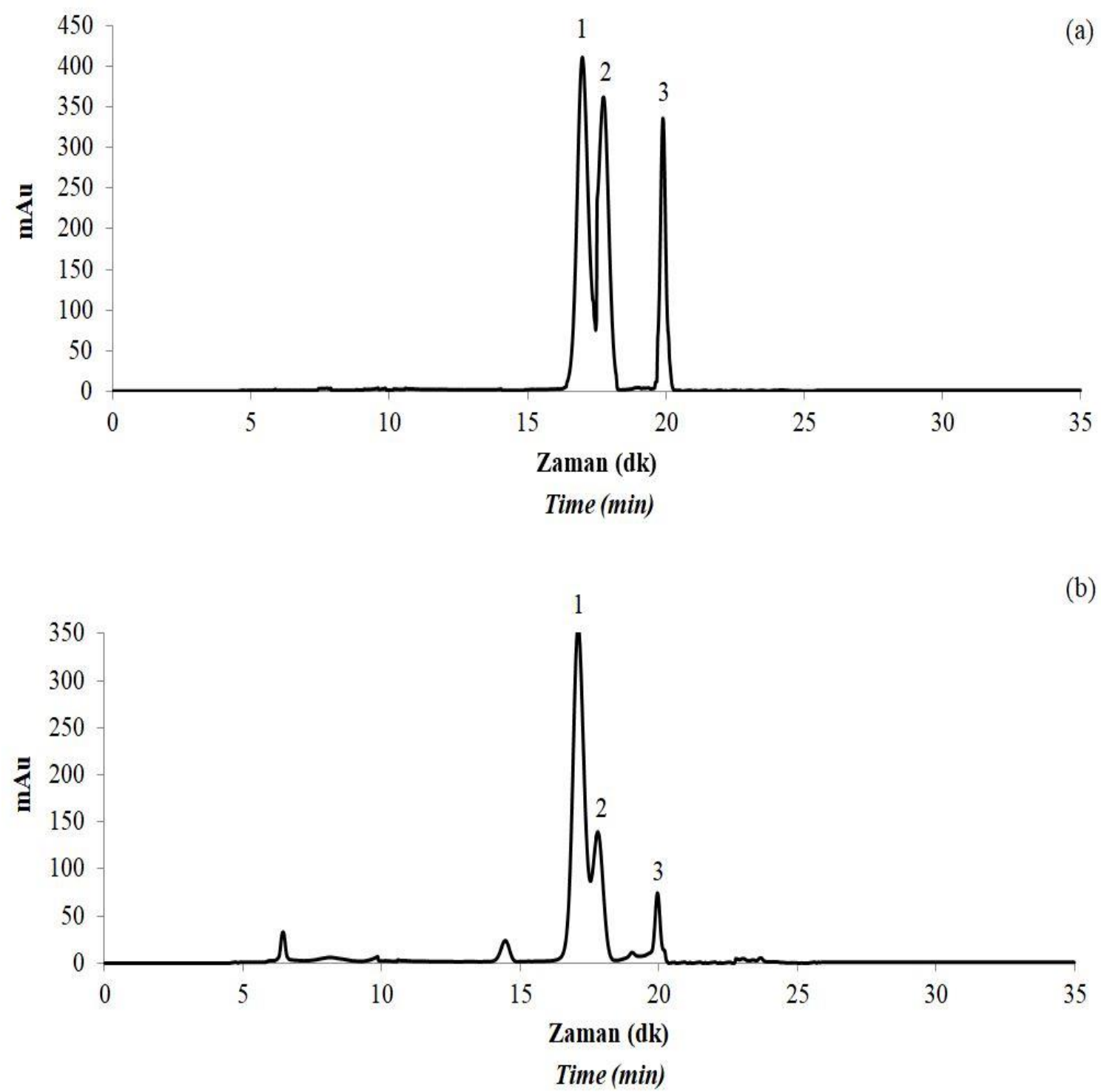

Şekil 2. Antosiyanin standartlarının (a) ve karadut suyunun (b) 530 nm'deki HPLC kromatogramları (1:siyanidin-3-glikozit, 2:siyanidin-3-rutinozit, 3:pelargonidin-3-glikozit)

Figure 2. HPLC chromatograms of anthocyanin standards (a) and black mulberry juice (b) at $530 \mathrm{~nm}$ (1:cyanidin-3glucoside, 2:cyanidin-3-rutinoside, 3:pelargonidin-3-glucoside) 
(a)<smiles>OCC1OC2OC(OC3C(O)C(O)C(O)C(O)C3O2)C1c1ccc(O)c(O)c1</smiles>

(c)

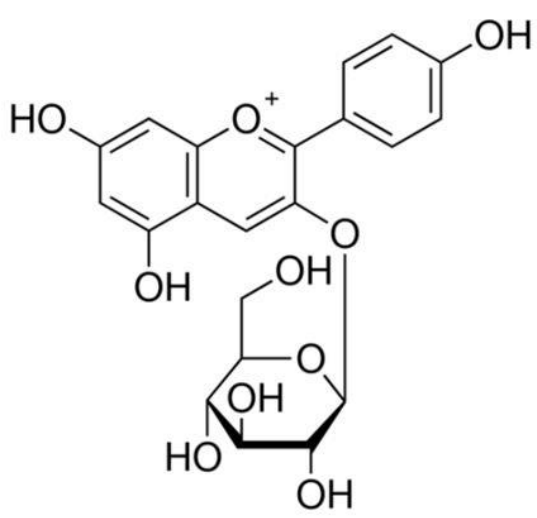

(b)

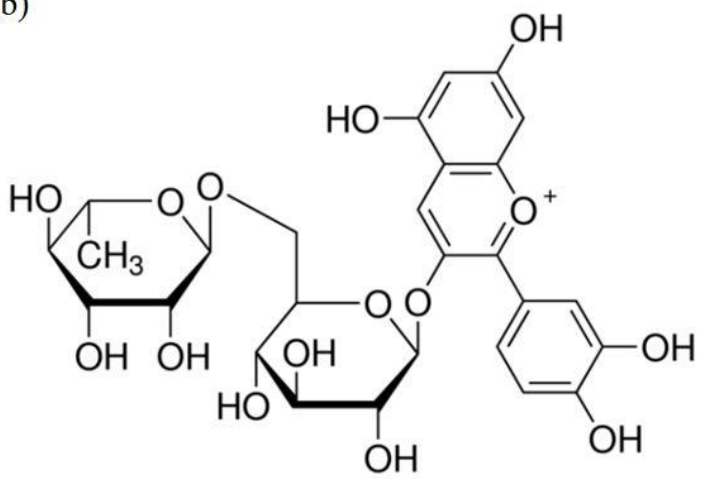

(d)

Şekil 3. Siyanidin-3-glikozit (a), siyanidin-3-rutinozit (b), pelargonidin-3-glikozit ve protokatekuik asit (d) moleküler yapiları

Figure 3. Molecular structures of cyanidin-3-glucoside (a), cyanidin-3-rutinoside (b), pelargonidin-3-glucoside (c), protocatechuic acid (d)

Antosiyanin ve antosiyanidinlerin insan ve fareler üzerine etkilerini inceleyen pek çok çalışma yapılmıştur. İnsan ve farelerde ağı yoluyla çeşitli siyanidin glikozitler alındığında plazmada antosiyanin ve antosiyanidinlerin varlığ farklı çalışmalarda gösterilmiştir (Galvano vd., 2004). Youdim vd. (2000) yaban mersini yedirdikleri farelerin plazmalarında siyanidin galaktozit, siyanidin arabinozit ve siyanidin tayin etmişlerdir. Yapılan benzer çalışmalarda da farklı antosiyaninler içeren gıdalar yedirilen insan ve farelerin plazmalarında antosiyaninler tespit edilmiştir. Böylece gıda yoluyla alınan antosiyaninlerin kan dolaşımına katıldığ gösterilmiştir. Siyanidinin DNA'yı koruyucu etkisi ilk kez Sarma ve Sharma (1999) tarafindan siyanidin ile DNA arasında bir kompleks oluştuğu öne sürülerek rapor edilmiştir. Bu kompleksin oluşumu hem siyanidini hem de DNA'yı özellikle hidroksil radikalinin saldırısı ile oluşan oksidatif hasardan koruduğunu belirtmişlerdir. Son yillarda yapılan çalışmalar antosiyaninlerin antioksidan özelliklerinin yanında antikanser, antimikrobiyal ve antiinflamatuvar gibi sağlığa yararlı başka özelliklerinin de bulunduğunu göstermektedir (Lin vd., 2017; Thibado vd., 2018).

\section{SONUÇ}

Karadutun içeriğindeki dört ana fenolik bileşik siyanidin-3-glikozit, siyanidin-3-rutinozit, pelargonidin-3-glikozit, protokatekuik asit olarak belirlenmiş ve kolon kromatografisi kullanılarak izole edilmiştir. Karaduta da rengini veren antosiyaninler zararsız ve doğal gida boyalan olmalarına rağmen saflaştırılmalarında yaşanan güçlükler kullanımlarını zorlaştırmakta ve 
yaygınlaşmasını engellemektedir. Karadutun içerdiği antosiyaninlerin moleküler yapıları birbirine çok benzer olduğundan birbirlerinden ayrilmaları oldukça zordur. Bu çalışmada karadut suyu ve fraksiyonlardaki antosiyanin miktarlarına bakıldığında \%80'in üzerinde geri kazanım sağlandiğ1 görülmektedir. Antosiyaninlerin pek çok gida ürününde renklendirici olarak kullanılması mümkündür. Antosiyaninler doğal renk verici maddeler olduğundan, birçok gidanın renklendirilmesinde sentetik boyar maddelere önemli bir alternatif oluşturmaktadır. Fiyatlarının yüksek oluşu kullanımlarının kısıtlı kalmasındaki en önemli etkendir. Yapılan bu çalışma ile ülkemizde yaygın olarak bulunan karadut meyvesinin antosiyaninler açısından zengin olduğu ve bu antosiyaninlerin saflaştırılarak gida ürünlerinde boyarmadde olarak kullanılmasının mümkün olduğu gösterilmiştir.

\section{ÇIKAR ÇATIŞMASI BEYANI}

Yazar, bu makalenin araşturilması, yazarlığ ve/veya yayınlanması ile ilgili potansiyel çıkar çatışması olmadığını beyan eder.

\section{KAYNAKLAR}

Ananga, A., Georgiev, V., Ochieng, J., Phills, B., Tsolova, V. (2013). The Mediterranean Genetic Code - Grapevine and Olive. In: Production of Anthocyanins in Grape Cell Cultures: A Potential Source of Raw Material for Pharmaceutical, Food, and Cosmetic Industries, Sladonja, B. (chief ed.), IntechOpen, the UK, pp. 247-287.

Aybastıer, Ö., Şahin, S., Demir, C. (2013). Response Surface Optimized Ultrasonic-Assisted Extraction of Quercetin and Isolation of Phenolic Compounds From Hypericum perforatum L. by Column Chromatography. Sep Sci Technol, 48: 1665-1674.

Chen, P.N., Chu, S.C., Chiou, H.L., Kuo, W.H., Chiang, C.L., Hsieh, Y.S. (2006). Mulberry anthocyanins, cyanidin 3-rutinoside and cyanidin 3 -glucoside, exhibited an inhibitory effect on the migration and invasion of a human lung cancer cell line. Cancer Lett, 235: 248-259.

Dalmagaro, A.P., Camargo A., Rodrigues A.L.S., Zeni A.L.B. (2019). Involvement of PI3K/Akt/GSK-3 $\beta$ signaling pathway in the antidepressant like and neuroprotective effects of Morus nigra and its major phenolic, bsyringic acid. Chem-Biol Interact, 314: 108843.

Espin, J.C., Soler-Rivas, C., Wichers, H.J., Garcia, V.C. (2000). Anthocyanin Based Natural Colorants; a New Source of Antiradical Activity for Food stuff. J Agric Food Chem, 48: 1588-1592.

Galvano, F., La Fauci, L., Lazzarino, G., Fogliano, V., Ritieni, A., Ciappellano, S., Battistini, N.C., Tavazzi, B., Galvano, G. (2004). Cyanidins: metabolism and biological properties, J Nutr Biochem, 15: 2-11.

Gündoğdu, M, Muradoğlu, F, Sensoy, RIG, Yilmaz, H, 2011. Determination of fruit chemical properties of Morus nigra L., Morus alba L. and Morus rubra L. by HPLC. Sci Hortic, 132: 37-41.

Hepsağ, F., Hayoğlu, İ., Hepsağ, B. (2012). Karadut Meyvesinin Antosiyanin İçeriği ve Antosiyaninlerin Gida Sanayinde Renk Maddesi Olarak Kullanım Olanaklan, Gida Teknolojileri Elektronik Dergisi, 7(1): 9-19.

Katsube, T., Imawaka, N., Kawano, Y., Yamazaki, Y. (2006). Antioxidant Flavonol Glycosides in Mulberry (Morus Alba L.) Leaves Isolated Based on LDL Antioxidant Activity. Food Chem, 97: 2531.

Khoo, H.E., Azlan, A., Tang, S.T., Lim, S.M. (2017). Anthocyanidins and anthocyanins: colored pigments as food, pharmaceutical ingredients, and the potential health benefits. Food Nutr Res, 61: 1361779.

Kostic, E., Arsic, B., Mitic, M., Dimitrijevic, D., Marinkovic, E.P. (2019). Optimization of the Solid-Liquid Extraction Process of Phenolic Compounds from Mulberry Fruit. Not Bot Horti Agrobo, 47(3): 629-633.

Kutlu, T., Durmaz, G., Ateş, B., Yılmaz, İ., Çetin, M.Ş. (2011). Antioxidant properties of different extracts of black mulberry (Morus nigra L.). Turk J Biol, 35: 103-110.

Lin, B.W., Gong, C.C., Song, H.F., Cui, Y.Y. (2017). Effects of anthocyanins on the prevention and treatment of cancer. $\mathrm{Br} J$ Pharmacol, 174: 1226-1243. 
Mahesh, D.S., Vidhathri, B.S., Vidyashree, D.N., Narayanaswamy, T.K., Subbarayappa, C.T., Muthuraju, R. (2017). Biochemical Composition and Pharmacological Properties of Mulberry (Morus spp.) - A Review. Int J Curr Microbiol Appl Sci, 6(7): 2207-2217.

Ovando, A.C., Hernandez, L.P., Hernandez, M.E.P., Rodriguez, J.A., Vidal, C.A.G. (2009). Chemical studies of anthocyanins: A review. Food Chem, 113: 859-871.

Özgen, M., Serçe, S., Kaya, C. (2009). Phytochemical and antioxidant properties of anthocyanin-rich Morus nigra and Morus rubra fruits. Sci Hortic, 119: 270-279.

Palonen, P., Weber, C. (2019). Fruit color stability, anthocyanin content, and shelf life were not correlated with ethylene production rate in five primocane raspberry genotypes. Sci Hortic, 247: 9-16.

Pelvan, E. (2020). Findiğın Polifenolik Maddelerinin Adsorban Özellikte Kolon Dolgu Maddesi Kullanilarak Fraksiyonlarına Ayrilması ve Elde Edilen Fraksiyonların Karakterizasyonu. Gida, 45(4): 613-622.

Polat, S.., Oğuz, İ., Attar, Ş.H., Değirmenci, İ., Nogay, G., Kafkas, E., Erdoğan, A. (2019). Baz1 Dut (Morus Spp.) Genotiplerinin Meyvelerinde Toplam Fenol İçeriklerinin Belirlenmesi. Bahçe, 48(1): 141-148.
Sarma, A.D., Sharma, R. (1999). AnthocyaninDNA copigmentation complex:mutual protection against oxidative damage. Phytochemistry, 52: 13131318.

Shekarabi, S.P.H., Omidi, A.H., Dawood, M.A.O., Adel, M., Avazeh, A., Heidari, F. (2020). Effect of black mulberry (Morus nigra) powder on growth performance, biochemical parameters, blood carotenoid concentration, and fillet color of rainbow trout. Ann Anim Sci, 20(1): 125-136.

Suh, HJ, Noh, DO, Kang, CS, Kim, JM, Lee, SW, 2003. Thermal kinetics of color degradation of mulberry fruit extract. Nahrung/Food, 47(2): 132135.

Uzun, H.İ., Bayır, A. (2010). Farklı Dut Genotiplerinin Bazı Kimyasal Özellikleri ve Antiradikal Aktiviteleri. III. Ulusal Üzümsü Meyveler Sempozyumu, 10-12 Haziran 2009, Kahramanmaraş, Türkiye, 128-138.

Thibado, S.P., Thornthwaite, J.T., Ballard, T.K., Goodman, B.T. (2018). Anticancer effects of Bilberry anthocyanins compared with NutraNanoSphere encapsulated Bilberry anthocyanins. Mol Clin Oncol, 8: 330-335.

Youdim, K.A., Shukitt-Hale, B., MacKinnon, S., Kalt, W., Joseph, J.A. (2000). Polyphenolics enhancered blood cell resistance to Oxidative stress: invitroand in vivo. Biochim Biophys Acta, 1523: 117-122. 